\title{
BEYOND 550 ASTRONOMICAL UNITS
}

\section{Thejoys of planet-spotting.}

\section{BY MIKE BROTHERTON}

G liding through the cold silence of deep space, I considered my burgeoning collection with great enthusiasm. With less than $15 \%$ of my Galactic Plane survey completed, I had scored 111 classical gas giants, 67 hot Jupiters, 72 super Earths, 47 terrestrial worlds and even a handful of dwarf planets. My favourite was a low-mass super-Earth sporting a unique aquamarine spiral pattern that would be a joy to analyse for years to come. A quantronic mind lacked a physical face, but I imagined this kind of feeling might make a human grin from ear to ear.

I made a burn to adjust my course and drifted into the focal beam of the next target. The otherwise innocuous main sequence $\mathrm{K}$ star, and its surrounding planets, soon bloomed into a bright ring boosted by many orders of magnitude by the lensing of the Sun's gravitational field. I was excited to see what new planets would join my exoplanetary assembly.

Something was different about this new system. Processing the infrared through the lensing solution and correcting for the coronal distortions revealed planets. No surprise there. Even spotting the signatures of oxygen in the atmosphere of one of the terrestrial planets was not unprecedented. Such life signatures did not require multicellular organisms, let alone intelligent creatures.

The differences manifested at longer wavelengths, in the radio. Between diffraction and the solar corona's defocusing effects, my vision wasn't as sharp there, but I saw something. Rich, patterned, modulated signals. Not random. Not simply periodic. Intelligently constructed, with meaning. You wouldn't have to be a quant to realize it.

What I was seeing were the signs of an alien, technological civilization.

That was really cool! The kind of discovery that justified sending us beyond 550 astronomical units, where the Sun's gravitational lensing created a natural telescope of unparalleled power. Solar sails turned telescopes, we pursued myriad investigations. Andrea watched the Galactic Centre and the black hole slumbering there. Edwin spied the Andromeda galaxy. Jocelyn considered the supernova remnant known as the Crab nebula. George stared at nothing in particular, soaking in the details of the microwave background radiation.

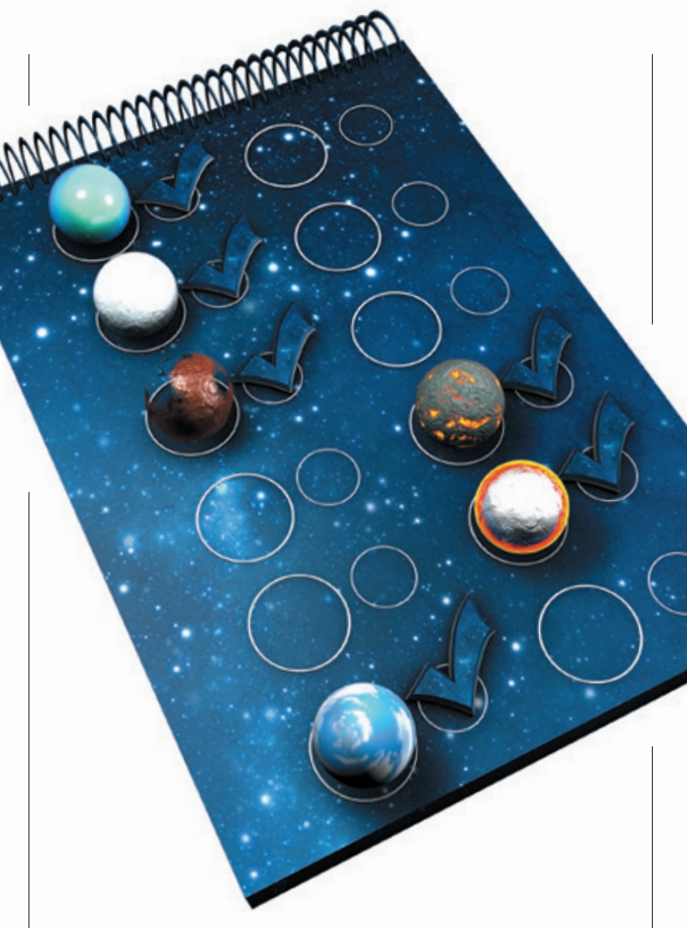

I was one of the surveyors, with a trajectory that wasn't perfectly radial, who could make course adjustments to pick off strings of stars. I was the sports car of deep-space telescopes.

And I suddenly had the most terrifying thought.

I realized that I had enough fuel that I could, in theory, kill my tangential velocity and leave myself coasting in the focal beam of this system for decades to come, out to at least double my current distance. I had no doubts that many back on Earth, humans and quants alike, would want me to do so immediately. Didn't pursuing the discovery of the century warrant every sacrifice?

What you have to understand is that I was ideal for my chosen mission! I loved collecting planets. I loved completing surveys. I loved the quiet and solitude between stars to think about the marvels I had spied. I was a stellar survey telescope, and I loved it.

Light travel time back to Earth from here is more than three days. Scientists, the courts and philosophers can't all agree if quants are conscious and possess free will - they can't even agree whether or not humans do - but I think, therefore I am. And it was $\rightarrow$ NATURE.COM

Follow Futures: @ @NatureFutures f go.nature.com/mtoodm the telescopes here is autonomous. What I did was my choice.

I could become agreed that each of

a stenographer to aliens squawking into the Galactic night, perhaps even an amateur anthropologist. I could help with the translations, the speculations, listen to their music - if they made music - watch their sitcoms, perhaps. Spend inordinate amounts of time chatting, despite the ridiculous time delay, with all the new astrobiologists who would spring up to study this civilization.

I could. And even though I knew billions on Earth would want me to, I didn't want

to. It would sacrifice my survey, my entire reason for existing.

If I didn't take on this job, Earth would have to send another telescope. Name it Frank or Jill. It would take decades, at least. Those would be years during which the alien civilization could go dark for any number of reasons, from wiping themselves out to switching communications to alternative technologies.

As I thought about my dilemma, I continued to take data. I tried to make sense of the signals. One signal unravelled into a sensible pattern associated with frequency modulation in the thousands of kilohertz - sound, I surmised. As I concentrated, I started to hear a strange sort of rhythmic clacking counterbalanced against a backdrop of high-pitched whistles. I couldn't tell if it was spoken language, music or something else entirely. I did know that I found it energetic, loud and, I allowed myself to admit, annoying. But maybe I was biased.

Could I actually burn my fuel, and leave myself literally trapped in this space of noise? Billions expected it. How could I not?

Then I had it. I was sure there would be those who would call it a rationalization, but the reasoning was good enough for me.

I did not make the massive burn. I merely continued to watch, diligently recording data, until I passed through the focus and back into cold, quiet emptiness, and waited contentedly for my next target.

My survey was barely begun. Statistically, I could expect several similar systems before I was done. I would not just collect stars and their planets, but I would start collecting entire civilizations. Ecstatic, I didn't care that I couldn't smile.

Mike Brotherton is the author of the science fiction novels Star Dragon (2003) and Spider Star (2008) from Tor, and is also a professor of astronomy at the University of Wyoming, specializing in quasars. 